San Jose State University

From the SelectedWorks of Grinell Smith

2013

\title{
Teaching care ethics: conceptual understandings and stories for learning
}

Colette Rabin, San Jose State University

Grinell Smith, San Jose State University 


\section{Teaching Care Ethics: Conceptual Understandings and Stories for Learning}

Colette Rabin

Assistant Professor,

San Jose State University, Elementary Education Department

One Washington Square

San Jose, California

95192-0074

Tel: 408.924 .3650

Fax: 408.924.3775

Email: colette.rabin@sjsu.edu

Grinell Smith

Assistant Professor,

San Jose State University, Elementary Education Department

One Washington Square

San Jose, California

95192-0074

Email: Grinell@gmail.com 


\begin{abstract}
An ethic of care acknowledges the centrality of the role of caring relationships in moral education. Care ethics requires a conception of "care" that differs from the quotidian use of the word. In order to teach care ethics more effectively, this article discusses four interrelated ways that teachers' understandings of care differ from care ethics: (1) conflating the term of reference "care" with its quotidian use, (2) overlooking the challenge of developing caring relationships, (3) tending toward monocultural understandings of care, and (4) separating affect and intellect. Awareness of these conceptions of care supports teacher educators to teach care ethics in more meaningful and relevant ways. We explore stories and their dramatization as a medium to facilitate effective and in-depth teaching of care ethics.
\end{abstract}


Care ethics is a relational ethic that recognizes the social and moral implications of all educative experiences. It provides an alternative to traditional moral education that separates ethical content from other subject areas and from experience. Referred to as a moral ecology (Author, 2012 in press), care ethics departs from an individualistic ethic (Gholami \& Tirri, 2012; Pang, 2005). In contrast, in a moral ecology relational ethicists view moral education as inextricably linked to each individual's influence since moral growth occurs in relationship. Preparing teachers to adopt care ethics requires teaching them to create the kind of caring relationships in which moral education can occur. Given that teachers socialize students in habits of mind that significantly affect their life chances, care ethics can play a critical role in helping teachers consider the moral implications of their beliefs and actions.

As teacher educators teaching care ethics, we have found that articulating the following conceptual misunderstandings can help teachers understand care ethics more deeply: first, care ethics counters today's educational climate that emphasizes standardization and quantitative assessment (Butin, 2005); second, it requires students to develop an understanding of "care" that differs from the quotidian use of the word; and third, care ethics requires in-depth study to understand its application in complex and authentic classroom settings. This article explores interrelated understandings associated with teaching about care ethics and discusses possible implications.

\section{Defining Care Ethics}

Care ethicist, Carol Gilligan, (1982) describes care as an ethic that focuses on responding to others" needs in relationships: "(T)he logic underlying an ethic of care is a psychological logic of relationships, which contrasts with the formal logic of fairness that informs the justice approach" (p. 73). Care ethics balances traditional moral education's focus on inculcating a set of 
virtues to be acted on in predefined ways. From an educational perspective, care ethics orients educators towards teaching students to care for themselves, each other, ideas and the world - and recognizing the demands of caring for students and how to meet their academic and social needs (Noddings, 1984, 1992, 2002a, 2002b, 2010).

Caring entails engrossing oneself in students' concerns enough to experience motivational displacement to act on their behalf. Noddings (2010) explains engrossment as receptive attention:

In a caring relation, the carer is first of all attentive to the cared-for, and this attention is receptive; that is, the carer puts aside her own values and projects, and tries to understand the expressed needs of the cared-for. (p. 391)

Care ethics highlights how we become increasingly able to relate within caring relationships through open-ended process-oriented experiences, such as modeling, practice, dialogue, and confirmation (Noddings, 2002).

Noddings (1984; 2002) and Mayeroff (1971) distinguish between caring about and caring for, pointing out that caring for requires reciprocity; thus, while we can care about those we do not know well, we can care for only those with whom we have built relationships. To care for requires the carer to understand an other's needs. To care for students, a teacher needs to know her students well enough to understand their unique motivations and needs. In such a relationship, a teacher as carer must balance her goals for the student - even those she assumes are in the student's best interest - in order to grapple with the student's own aspirations (Goldstein, 1998; Pang, 2005). Ultimately reciprocity characterizes the caring relation (Noddings, 2010). 
Caring about refers to care extended to groups. Noddings (1999) offers an example of how caring-about a group might fall short of caring for individuals within that group:

(W)hen policy makers decide to eliminate the discrimination inherent in hierarchical tracking by forcing all students to take the courses once required only of students preparing for college, the talents and interests of many students are ignored, even denigrated. (p. 1)

Here the concept of caring about clarifies why a policy, such as one that standardizes curriculum for all students, falls short of caring for. Understanding both of these concepts - caring for and caring about - illustrates that the recipient must be involved in determining whether or not an act represents caring. Thus, to care for others, the carer must endeavor to know the cared fors well enough to interpret what care means in their contexts; thus, enacting care ethics in multicultural and group contexts heightens the challenge.

\section{Addressing Care Ethics in Teacher Education}

Over the past two decades, scholars have critiqued teacher preparation programs for overlooking the ethical and dispositional aspects of teaching and learning. (See, for example, Goodlad et al, 1990; Huebner, 1996; Lake et al, 2004; Sockett \& Le Page, 2002). In response to this need, some teacher preparation programs have begun to address dispositions, and to integrate care ethics across the curriculum from this perspective (Author, 2008; Koeppen \& Davidson-Jenkins, 2007; Schussler et al, 2010; Sockett \& Le Page, 2002). Systemic efforts to address teacher dispositions have also been initiated. For example, the National Council for Accreditation of Teacher Education (NCATE) mandates that teacher educators focus on teachers' dispositions as well as their skills and knowledge, and highlights two core dispositions:

1) being fair and 2) believing that all students can learn (2008). Usage of the term dispositions 
has varied widely in the research literature (Schussler et al, 2010; Author, 2010; Authors, in press; Authors, in review). Drawing on Dewey's (1922) focus on the importance of habits of mind in teaching, Ritchhart (2001) argues 'dispositions' bridge the gap between skills and how we are actually inclined to act. Gradle (2007) defines dispositions as one's 'tendencies to 'be' in a particular way in a classroom" (p. 7), noting that one's beliefs and values guide one's actions. In a review of the research, Hillman et al (2006) reports: "Educational research has long noted that dispositions such as self-efficacy, high expectations, an ethic of caring (italics added), sensitivity to others, and reflective capability [are]... critical components to being an effective teacher" (p. 234).

Affecting teachers' dispositions presents a worthy and deep challenge (Gradle, 2007; Schussler et al, 2010). For example, despite her attempts to address dispositions, Gradle (2007) noted only temporary impact in her students' dispositional growth. Schussler et al (2010) found that pre-service teachers lacked self-awareness about their dispositions to care, and questioned how the likelihood of their meaningfully integrating moral values associated with their teaching practice without opportunities for self-reflection.

To help teachers develop a deep understanding of care ethics, teacher educators must understand prevailing conceptions concerning care's meaning and how these conceptions differ within care ethics. Researchers note several obstacles to learning about the concept of care: traditional notions of care reveal limited Western notions of femininity (Vogt, 2002); reflect color-blindness or cultural neutrality (Jones et al, 2001; Knight, 2004; Wilder, 1999); or inform and refer only to the affective realm (Goldstein, 1998). Conceiving of care in these limited ways, teachers may legitimately claim that they "care" about their students. Interestingly, however, most students report that in their entire experience of schooling they had less than five teachers 
who "cared," in the sense of the word as it is used in the context of care ethics (Thayer-Bacon et al, 1998). How can teachers learn to draw on care ethics - as more than a "feminine feeling," explore what it means to care across cultural and racial divides, and thus open to the possibilities of teaching care ethics deeply?

\section{Understanding Care Ethics}

As teacher educators teaching care ethics, we have found acknowledging and reframing the following four interrelated conceptions of "care" that differ from the use of the concept within care ethics (Author, 2008, 2010): (1) conflating the term of reference "care" with its quotidian use, (2) failing to acknowledge the challenge of constructing caring relationships, (3) tending toward monocultural understandings of care, and (4) separating affect and intellect.

Going beyond the quotidian use of the word "care." To teach care ethics effectively, obstacles to adopting this theoretical perspective need articulation. Deceptively simple connotations surround the term, care, and popular discourse frames social dimensions of education as expendable, simple, or as the obvious and "soft side" of teaching (Krazny, 2013). Especially when high stakes standardized testing narrows educators' focus to specific cognitive skills, theoretical frameworks such as care ethics occupy an inferior position to more "practical" aspects of teaching such as standards and assessment (Butin, 2005). Not surprisingly, researchers have found pre-service teachers' understandings of care did not extend beyond a warm-fuzzy, feminine, or static personality trait that cannot be learned - associated with the feminine or maternal (Goldstein \& Lake, 2000) or as a superficial, patronizing, or nice personality trait diluted in generalities, as expressed in this statement: 'Of course I care' (White, 2003) (also see for example, Lake et al, 2004). 
In a previous study of a teacher preparation program committed to care ethics by one of the authors $(\mathrm{XXXX})$, the graduates evoked static personality traits when asked what care ethics means to them in the context of teaching. For example, one said, "(T)his principle is simple to me and I feel I understand it. To want to teach means the person must be nice, be caring." While we agree that teachers "be caring," we also recognize we need to prepare them to reflect on their teaching from the perspective of care as an ethic, and to describe this application, to explain their decision-making processes, for example, as they respond to students' disruptions and questions, evaluate students, and try to develop relationships with them. As teachers of an ethic of care, we need to disambiguate the common use of the word "care" with what the word means in the context of care ethics. Since mental models persist when not directly challenged, understanding common usage of care supports constructing new meanings within care ethics.

This points to the need for opportunities to reframe quotidian and stereotypical notions of care toward richer and more grounded understandings.

\section{Acknowledging the challenge of developing caring relationships. Teachers who}

practice an ethic of care consider developing relationships to be artfully complex and at the same time critical to a learning environment where students feel safe to take the risks that real learning requires (Charney, 2002; Nias, 1999; Thayer-Bacon et al, 1998; Watson, 2003). The relational nature of teaching needs to be made visible to teachers. If teachers do not learn to create caring relationships, they will default to quick-fix extrinsic control measures to gain student compliance, rather than care-focused classroom management methods that create a safe and caring classroom environment (Bondy, 2007; Charney, 2002; Rosiek, 1994; Watson, 2003).

Developing a multicultural understanding of care. The increasing racial and cultural diversity of our schools compounds the complexity of fostering caring relationships and 
heightens the importance of developing multicultural understandings of care (Wilder, 1999; Delpit, 2006; Knight, 2004). In order to challenge culturally-bound conceptions of care, teachers need to question their implicit beliefs and assumptions given, for example, that communication styles differ (Nieto, 1999). Yet to be prepared for the reciprocity necessary to care, teachers must explore how their own and their students' efforts to care might be misunderstood. Thompson (1998) writes about the need to resist the tendency to "look for the culturally White practices and values that... theory...already recognize(s) as caring" (p. 531). In a case study of conceptions of care held by teachers of color (Author, 2010), one teacher describes how she interpreted her student's intentions within a verbal exchange:

I myself - being an African-American - we don't talk in any sort of order. What I find is, when African-American students start to feel included they start talking over me and each other. This shows they have started to like me and it's not trying to defy. Teachers need to understand that.

Another teacher might have viewed the same exchange as demonstrating defiance, rather than evidencing the growth of a caring relationship. This illustrates the importance of looking past a particular behavior for the underlying intention; and of recognizing that students may express care through a variety of norms particular to cultural and background experiences.

Teachers need to recognize when we teach cultural norms as taken-for-granted and unquestioned, for example, the cultural specificity of Western beliefs about expressing and regulating emotions through talking about them (Tobin, 1995). A deep awareness that schemas differ widely can balance our beliefs concerning how 'best' to work through relational struggles. Paying lip service to culturally different understandings of care and teaching students our own ways of relating cannot suffice for care. 
Integrating the affect and the intellect. The tendency to separate affect and intellect and view affect as less valuable has a long history in Western cultures (Plato, n.d.). Our students often express this tendency with comments like, "I wasn't hired to care. I was hired to know my content." Current emphases on academic performance underscore this circumscribed view. Instrumentalist arguments often link care and academic gains with for example, policies that advocate for programs concerned with the socio-emotional needs of kids because they seem to raise test scores (e.g. the Department of Education's "What Works" clearinghouse) (Hoffman, 2009). However, justifying care's worth or measuring its quality with the yardstick of academic gains limits our understanding of care's purposes and continues to position its worth below thought. This belies age-old philosophical arguments over the inadequacy of such binaries and neurological research showing that thought and emotion intimately colored one another (Pinker, 2000). Hoffman (2009) argues:

Unless a parallel emphasis is placed on the qualities of relationship that arguably should contextualize skills and behaviors, the discourse risks promoting a shallow, decontextualized, and narrowly instrumentalist approach to emotion in classrooms that promotes measurability and efficiency at the expense of (nonquantifiable) qualities of relatedness (p. 539).

The interrelation of affect and intellect underscores that learning to care requires more than mastery of additional strategies; it requires a fundamental shift in teacher preparation. It asks us to teach teachers that caring involves our rationality and our emotionality in equal measure; to encourage a willingness to take on the "emotional labour" of teaching (Isenbarger \& Zembylas, 2006; Hargreaves, 2000). As teacher educators drawing on care ethics to explore the 
emotional terrain of teaching, we ask, "How can teacher education prepare teachers for more nuanced understandings of care theory?"

\section{Implications for Teacher Education}

To support teachers' learning care ethics, they need opportunities to cull forth preexisting mental models of care to contradict misunderstandings. Ultimately, teachers need to transcend the seeming divide between theory and practice.

\section{Translating Theory into Stories}

As we grapple with how to teach care ethics deeply, we have found that personal narratives help our students begin to make connections to their own experiences, and thus become a form of shared inquiry (Author, 2012). As one of our students noted, "stories put the flesh on the bones. They help me think about a theory or an idea in a real setting, which keeps me from skimming over the details." Another wrote, “To me, the stories are important. They're great tools to 'think with'." Stories of practical application can reveal pre-conceptions and deepen care's meaning since they encompass broad dimensions of human experience (Polkinghorne, 1988; Connelly \& Clandinin, 1990).

One such story that helps "put the flesh on the bones" of care theory involves a relationship with Ivan, a young boy who struggled with issues of defiance at school. I (author 2) used this story to illustrate the importance of taking the cared-for's perspective into account. This story also reveals something about the complexity of authentic situations and the need to transcend the binary view of "getting things right or wrong." In class, I related this story in two parts, with discussion in between.

Part I: Ivan, a $5^{\text {th }}$ grader, was quick with words, a linguistic gymnast with an impish sense of humor that often bordered on insolence. He also had the reputation as an 
adversarial kid with a short fuse. Many of his teachers struggled to maintain control of their classes with Ivan because of Ivan's ability - and willingness - to derail discussions and activities, and he was known as a "frequent flyer" because of his numerous trips to the office. The general opinion of teachers, however, was that Ivan was a very intelligent boy with tremendous potential, academic and otherwise, despite his disruptive behavior and poor academic performance.

Although at times I found Ivan challenging, I genuinely appreciated his wit and humor, and decided to learn more about him, visiting his home several times. As I left his house one Saturday, Ivan's mother introduced me to a friend, Robert, who told me he had promised Ivan a bicycle if he "stopped getting in trouble and made good grades." I saw Robert again, and when he asked how he was doing at school, I gave him a $\$ 20$ bill toward Ivan's new bike by way of a response.

After part I of this story, I asked my students what they might glean. Discussion centered on intrinsic versus extrinsic motivation, and the power of "getting to know a student outside of school." When we had discussed these concepts in some depth, I shared part two of the story.

Part II: One day, about a week after I had given Robert the \$20, I saw Ivan riding a new bike. When I asked him about it the next day, however, he said his mother had taken it away. A little digging revealed that (a) Robert had made the bike deal with Ivan without the knowledge or approval of his mother, and (b) his mother was mad at all three of us: Robert for lavishing such a gift on him in a way that she felt undermined her efforts to discipline him; Ivan for "manipulating Robert for selfish reasons;" and me for "meddling in her business." 
This discussion centered on my actions, and prompted us to question how to cultivate caring relationships with our students. Were my actions caring? Did they exhibit caring for or caring about? Where was the boundary between her and my "business?" In this context, my students considered what the role of caring teacher demands, what Noddings meant by engrossment. Through this story, students came to see that while I may have cared about Ivan, my failure to engross myself in his concerns left my actions short of caring for him. Thus, it illustrated two important concepts underpinning care ethics: the necessity of engrossment to enable one to go from caring about to caring for, and the challenge of building relationships that enable that leap.

Another story, about Tim, centers on confirmation, a commonly misunderstood conception central to care ethics that Noddings (2010) affirms "as among the loveliest of moral gestures" (p. 305). Educators often misinterpret the concept of confirmation by conflating it with encouraging 'high standards,' reflective of the elevation of intellect over affect. We may describe, for example, tell a student "good job" to confirm a student's intention, when in fact it may instead confirm a behavior. To confirm a student's intention, however, demands more than affirming "good" behavior. The teacher as carer must situate a student's actions within an understanding of possible underlying motives, and act to encourage the positive:

When we confirm someone, we spot a better self and encourage its development.... Formulas and slogans have no place here. We do not set up a single ideal or set of expectations for everyone to meet, but we identify something admirable, or at least acceptable, struggling to emerge... Confirmation requires attribution of the best possible motive consonant with reality. (Noddings, 1995, p. 25) 
Confirmation as Noddings describes it implies the possibility of an intention to do good even if we consider an agent's behavior less than admirable.

Tim's story: Tim struggled for years (from kindergarten to fifth grade) to admit culpability or involvement in altercations in which he hurt other children. One day on the playground Tim lost his temper, grabbed a soccer ball from Sam, and hurled it at Sam's head from behind, then stormed off and sat alone. I (Author 1) joined him, sitting nearby and expecting the usual litany of judgments about the person he hit, offered as justifications for his actions, along with a refusal to admit his role in the situation. I was ready to express my disappointment at Tim's repeated blame and avoidance. However, I hesitated, remembering how rebuking him over the years had not worked. And as I sat beside him, I thought about the event from his perspective, and knowing him quite well, I tried to imagine what he might be thinking. After a time, instead of a rebuke, I said, "Here we are in one of these situations again, Tim, where you're sitting aside." We sat for a long time in silence. Finally, he said slowly, 'Well... I did hit him.'

Although I found Tim's behavior less than admirable, I chose to try to confirm this glimmer of responsibility, which I interpreted as hinting at his best intention. I replied, 'I appreciate your telling the truth.' I listened to his perspective and suggested that he admit his guilt to Sam.

I based my choice on knowledge of Tim's home life. Tim's terminally ill mother had recently lost her job, leaving Tim often alone at home. At school, in attempts to shield other children from his harmful outbursts, we teachers often isolated him from his peers. In this instance, however, I chose not to act based on assuming his negative intention, but rather to confirm the possibility of Tim's halting progress toward accepting responsibility. Perhaps my choice to confirm what I construed as courageous and truthful communication engendered a 
sense of safety that allowed him, finally, to begin to talk about his troubling behavior. As Noddings (1995) put it, perhaps I had become for Tim a "significant and percipient other who sees through the smallness or meanness of my present behavior a self that is better and a real possibility" (p. 25).

This story prompted discussion about meeting a cared for's needs in a way he or she can understand. Students respond to the following questions in pairs first, and then the larger group, to encourage candid consideration. How can we know if a response was caring? How might Tim have understood why I didn't rebuke him? Sam? As the teacher, what would you say to Tim and Sam? Here we can draw on the opportunity to dig deeper into what caring entails by acting out a story.

\section{Taking Stories Further: Performance Studies}

In addition to discussing such stories, students can act out roles to engage in decisionmaking and consider multiple courses of action in light of their understandings of an ethic of care. In so doing, students distinguish between care's common usage and what it could mean to assume a care ethic in the particular situations they encounter in the classroom. As instructors in teacher education, we draw on Richert's (2012) compendium of stories, as well as our students' own stories gathered from their experiences in classrooms during their practica. Students' own stories have addressed a multitude of scenarios, from the dilemmas of grading a student to balancing the needs of one student with those of the whole class. The complexity of caring becomes readily apparent as teachers improvise and then reflect on how they interpret and choose in a given situation. Dramatizing stories allows learners to experience practicing and reflecting on caring habits of mind.

Educators have explored the possibilities for constructing deeper experiences for learning 
an ethic of care through acting out stories. In particular, Hamington (2010) approaches an ethic of care through dramatization from the perspective of Dewey's notion of dramatic rehearsal. Dewey's dramatic rehearsal focuses on the elements in theatre of playfulness, intimacy with the story and the characters. Hamington theorizes that dramatic rehearsal can provide a holistic method of moral reflection from a care ethics perspective since the participants experience a story from the "inside out." Along these lines, several researchers have explored dramatizing stories in the classroom. For example, Jones (2002) employed "performance studies" in her literature course for her students to experience cross-cultural role-taking. Through acting out stories and assuming roles in which her students played characters from different cultures, they interrogated stereotypes and unearthed their constructions of self and other. Jones (2002) writes about the possibilities of performance studies for learning across racial and cultural differences: "As teachers and students we must be willing to do the terrifying work of examining our selfconstructions and our rigidly held constructions of others, if we are to create a truly liberatory education. Performance can be a vital tool in that liberation" (p. 187). In another context of nursing education, Vanlaere, Coucke, and Gastmans (2010) simulated a two-day "care ethics lab" in which one student assumed the role of the care-giver and another an elderly care recipient. The pair engaged in reflective dialogue pre and post simulation, critiquing their dramatization of care with their understanding of what it means to provide "good care." In an elementary all school play (Author, 2009), k-middle level students learned to care across differences of race, gender and class - and deepened their commitment to the historical content of the play.

Ultimately, dramatizing stories to teach an ethic of care in teacher preparation begins to address the need for revised pedagogies that more closely approximate elements of practice 
(Grossman et al, 2009). In order to develop deeper learning experiences concerning theoretical perspectives such as care ethics, theatrical rehearsal of stories allows learners to reflect over their decisions in improvisations. Stories like these counteract some of the misconceptions of teaching an ethic of care by hinting at its complexity. They can clarify the breadth of understanding hinted at in a purely theoretical description of care ethics by highlighting that caring across the distance between a teacher and a student requires accepting the challenge of knowing him and his world and that doing the "right" thing may not follow because one is caring.

\section{Conclusions}

To prepare teachers to translate the theory of care ethics into practice, we suggest reflective dialogue and dramatization of vignettes and stories designed to unearth preconceptions and to offer opportunities for shared inquiry (Author, 2012; Author, 2008). Instructors can embed such stories in foundations and methods courses throughout teacher preparation. Stories can also grow out of field placement courses as teachers' relationships with children develop. hooks (1994) reminds us of the promise of this endeavor:

To teach in a manner that respects and cares for the souls of our students is essential if we are to provide the necessary conditions where learning can most deeply and intimately begin. (p. 13)

We see the theory of care ethics translated to practice as a route to creating those conditions. 


\section{References}

Bondy, (2007). Creating Environments of Success and Resilience: Culturally Responsive Classroom Management and More. Urban Education, 42, 4, 326-348

Butin, D.W. (2005). How social foundations of education matters in teacher preparation: A policy brief. Educational Studies, 38, 241-229.

Charney, R. S. (2002). Teaching children to care: Classroom management for ethical and academic growth, $k-8$. Northeast Foundation for Children: Turners Fall, MA.

Connelly, F. M. \& Clandinin, J. (1990). Stories of experience and narrative inquiry. Educational Researcher, 19, 2-14.

Delpit, L. (2006). Other peoples' children: Cultural conflict in the classroom. New York: The New Press.

Dewey, J. (1922). Human nature and conduct. In The middle works of John Dewey, 18991924, V. 14. Carbondale: Southern Illinois University Press.

Dottin, E. S. (2009). Professional judgment and dispositions in teacher education. Teaching and Teacher Education, 25, 1, 83-88.

Gholami, K. \& Tirri, K. (2012). Caring teaching as a moral practice: An exploratory study on perceived dimensions of caring teaching. Education Research International, 1-8.

Gilligan, C. (1982). In a Different Voice. Cambridge: Harvard University Press.

Goldstein, L. (1998). Taking caring seriously: The ethic of care in classroom life. Paper presented at the meeting of the Annual Meeting of the American Educational Research Association, San Diego, CA.

Goldstein, L. \& Lake, V. E. (2000). “Love, love, and more love for children”: Exploring 
preservice teachers' understandings of caring. Teaching and Teacher Education, 16, 861872.

Goodlad, J. I., Soder, R., \& Sirotnik, K. A., (1990). Places where teachers are taught. San Francisco: Jossey-Bass.

Gradle, S. (2007). Random weave: Developing dispositions to teach art. Art Education, $60,4,6-11$.

Grossman, P., Compton, C., Igra, D., Ronfeldt, M., Shahan, E., \& Williamson, P. (2009). Teaching practice: A cross-professional perspective. Teachers College Record, 111(9), 2055-2100.

Hamington, M. (2010). Care ethics, John Dewey’s ‘dramatic rehearsal,' and moral education. Philosophy of Education Yearbook.

Hargreaves, A. (2000). Mixed emotions: teachers' perceptions of their interactions with students. Teaching and Teacher Education, 16, 8, 811-826.

Hillman, S. J., Rothermel, D., Scarano, G. H. (2006). Promising practice: The assessment of preservice teachers' dispositions. The Teacher Educator, 41, 4, 234-250.

Hoffman, D. M. (2009). Reflecting on social emotional learning: A critical perspective on trends in the United States. Review of Educational Research, 79, 533-556.

Huebner, D. (1996). Teaching as moral activity. Journal of Curriculum and Supervision, $11,267-275$.

Isenbarger, L. \& Zembylas, M. (2006). The emotional labour of caring in teaching. Teaching and Teacher Education, 22, 120-134.

Jones, E. B., Pang, V. O., Rodriguez, J. L. (2001). Social studies in the elementary classroom: Culture matters. Theory into Practice, 40, 35-41.

Joni L. Jones, "Teaching in the Borderlands" in Teaching Performance Studies, eds., Nathan 
Stucky and Cynthia Wimmer (Carbondale, IL: Southern Illinois University, 2002).

Kohn, A. (1996). Beyond discipline: From compliance to community. Upper Saddle River, NJ: Prentice Hall.

Knight, M. G. (2004). Sensing the urgency: envisioning a black humanist vision of care in teacher education. Race, Ethnicity, and Education, 7, 211-227.

Lake, V. E., Jones, I., \& Dagli, U. (2004). Handle with care: Integrating caring content in mathematics and science methods classes. Journal of Research in Childhood Education, $19,5-17$.

Mayeroff, M. (1971). On caring. New York: Harper and Row.

Nias, J. (1999). Primary teaching as a culture of care. In J. Prosser (Ed.), School culture (pp. 66-82). London: Paul Chapman.

Nieto, S. (1999). The light in their eyes: Creating multicultural learning communities. New York: Teachers College Press.

Noddings, N. (1984). Caring: A feminine approach to ethics and moral education. California: University of California Press.

Noddings, N. (1992). The challenge to care in schools. New York: Teachers College Press.

Noddings, N. (2002a). Educating moral people: A caring alternative to character Education. New York: Teachers College Press.

Noddings, N. (2002b). Starting at home. New York: Teachers College Press. Noddings, N. (2010). Moral Education in an Age of Globalization. Educational Philosophy and Theory, 42, 4, 390-396. 
Pang, V.O. (2005). Multicultural education: A caring-centered approach, $2^{\text {nd }}$ edition. Boston: McGraw Hill.

Pinker, S. (2000). The language instinct. New York: Perennial Classic.

Plato. (n.d.). The republic.

Polkinghorne, D. E. (1988). Narrative knowing and the human sciences. New York: State University of New York Press.

Ritchhart, R. (2001). From IQ to IC: A dispositional view of intelligence. Roeper Review, $23,3,143-50$.

Rosiek, J. (1994) Caring, classroom management, and teacher education: The need for case study and narrative methods. Teaching Education, 6, 21-30.

Schussler, D.L., Stooksberry, L.M., \& Bercaw, L. A. (2010). Understanding teacher candidate dispositions: Reflecting to build self-awareness. Journal of Teacher Education, 61, 350-363.

Slote, M. (2007). The ethics of care and empathy. London: Routledge.

Sockett, H. \& Le Page, P. (2002). The missing language of the classroom. Teaching and Teacher Education, 18, 159-171.

Thayer-Bacon, B. J., \& Arnold, S., \& Stoots, J. (1998, April). Identification of caring professors in teacher education programs. Paper presented at the Annual Meeting of the American Educational Research Association, San Diego, California.

Thompson, A. (1998). Not the color purple: Black feminist lessons for educational caring. Harvard Educational Review, 68, 522-546.

Tobin, J. (1995). The irony of self-expression. American Journal of Education, 103, 233238. 
Vanlaere, L., Coucke, T., and Gastmans C. (2010) Experiential learning of empathy in a careethics lab. Nursing Ethics. 17, 3, 325-336.

Vogt, F. (2002). A caring teacher: Explorations into primary school teachers' professional identity and ethic of care. Gender and Education, 14, 251-265.

Watson, M. (2003). Learning to trust. Jossie-Bass: California.

White, B. (2003). Caring and the teaching of English. Research in the Teaching of English, 37, 295- 328.

Wilder, M. (1999). Culture, race, and schooling: Toward a non-color-blind ethic of care. The Educational Forum, 63,356-62. 